\section{Techno farming}

\section{Sheldon Krimsky}

Plants, Power and Profit. By Lawrence Busch, William B. Lacy, Jeffrey Burkhardt and Laura R. Lacy. Blackwell: 1991. Pp.275. £35, \$39.95.

IT is now almost a cliché that agriculture is poised for a new stage in its industrial development by virtue of the scientific advances in biotechnology. The vast machinery of the world's agricultural research and development (R\&D) sectors are in a highly competitive race to develop new 'miracle', seeds or other adjuvants that can extract another ounce of productive efficiency from the farm or bring new land under cultivation. The cornucopians are buzzing and the malthusians are watching in disbelief. What about all those projections of food scarcity in the year 2000 ? Will they have to be recalculated?

Expectations for the role of recombinant DNA technology in agriculture include ecologically safe solutions to pest control, a reduction in the chemicalization of farming towards a more sustainable use of land resources, and the removal of climatic impediments to food production through the redesign of plant genomes. We are not at a point yet where these goals can be evaluated. But we do know that a great deal of promise has been placed on biotechnology. The industrialized nations, and particularly those

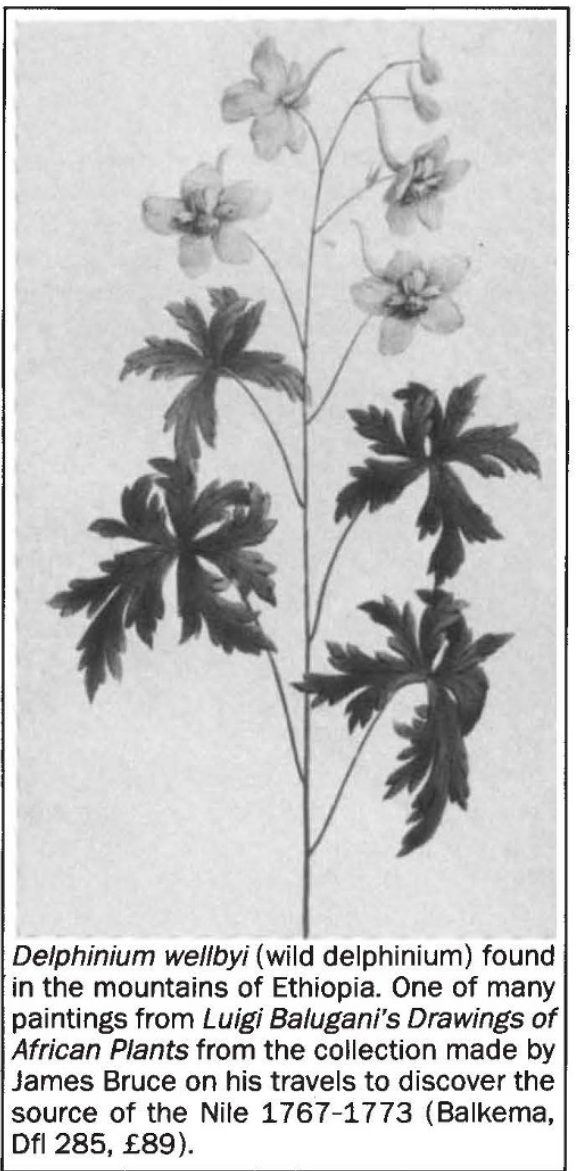

strong in the biosciences, have given plant molecular genetics a preferred status in the agricultural R\&D sector.

Plant, Power and Profit makes a credible effort to provide a progress report on biotechnology's impact on agriculture. We will need many such efforts by social scientists to keep pace with the momentum of the agricultural research enterprise. This work grew out of a multidisciplinary research project that claims to have garnered over 200 interviews with leaders in all aspects of agricultural research and development. The book tries to do a great deal and can easily be faulted for never quite fulfilling some of its tasks. But the tradeoff, and I believe well worth it, is that its analysis is broad, intellectually provocative, and seeks an integration of science, technology, policy and values.

After an obligatory introductory chapter on trends in biotechnology that gets bogged down in statistics, a second chapter is devoted to sociology and philosophy of science and their relationship to agricultural research systems. A third chapter summarizes a literature that is quite familiar to historians of biology, namely, the origins of molecular genetics and the role of the Rockefeller Foundation in transforming biomedical science. Two additional well-crafted chapters provide an in-depth analysis of the science and political economy of two crops, wheat and tomatoes. The role of biotechnology is discussed briefly because its research applications to these crops are as yet unrealized. Nevertheless, these case studies provide important insights on the origins of technological innovation for these crops and serve as a useful framework for examining other agricultural products. There are no surprises in these analyses. The research effort is responding to new segmented markets (yuppie tastes such as specialty wheat) or to more efficient processing (wheat for easier milling; tomatoes designed for better harvesting). The authors are somewhat sceptical of the myth that in biotechnology we can have an 'efficient' tomato that preserves a semblance of good taste. The essential role of biotechnology, according to the authors, is that "it gives farmers factory-like control over their farming process." For the genetically-engineered tomato it means higher solids and acid content, a uniform colour, and a square shape for machine picking and packaging. All in all, biotechnology is heading toward the complete hegemony of the technological farm.

Two other chapters that address ethical and policy matters are less satisfying because their analysis fails to go far enough. The principal theme is stated succinctly: "We will argue that a 'national biotechnological impact assessment program' should be established. Not just ex post facto regulation of social environment or agricultural effects of biotechnology, but also an agenda that would attend to the broader socioeconomic and structural effects that might be expected." Very little attention is devoted to how such a programme would be carried out.

One thing seems very clear. In contrast to other major technological developments, biotechnology is starting out on a new playing field. The social expectations of this technological revolution are different than the past. Until this is understood, the true character and meaning of the public response will be obfuscated. In this new playing field, many of the constraints of traditional crop breeding have been removed. The role of the university and its ties to industry are being reexamined. There are social demands for a new approach to regulation that include more than environmental and health effects. Moreover, the traditional approach of regulating proven hazards has been supplanted by an approach that would regulate speculative or potential hazards. Finally, in this new playing field one dares to select out a process for regulation setting it apart from the long tradition of Euro-American environmental policy that is product-oriented.

Industrial spokespersons are perturbed, quite understandably, by advocates who wish to change the rules of the regulatory process. This has become patently obvious in the case of the controversies over bovine somatotropin (BST) and herbicide-resistant transgenic plants. According to their proponents, if these products do not present a clear hazard to humans or the environment, then what grounds can there be for disapproval? The authors state but do not provide a systematic argument, that such grounds are credible. They call for a "national biotechnological assessment program" in the United States, one that will also help direct the goals of agricultural research.

At stake is nothing less than who controls agricultural technology. Richard Levins and Richard Lewontin argue in their pathbreaking analysis of science policy, The Dialectical Biologist (Harvard, 1985), that "The direction of technical change in capitalist agriculture and the research strategies that support this direction are the results of two kinds of factors: the quest for profit by industry and the pursuit of social control by the capitalist class as a whole." Most indicators suggest biotechnology will reinforce this result. Indeed, current state-supported science has an interest in corporate-oriented technological innovation. In the United States this is highlighted by the role the White House Council on Competitiveness has been playing in softening any regulation of biotechnology. Plants, Power and Profit makes a valuable contribution to this debate by its careful examination of the sources of innovation in agriculture, by highlighting the contradictory tendencies for the use of agricultural biotechnology, and by daring to pose an alternative, albeit opaque, vision for social governance of agricultural development.

Sheldon Krimsky is in the Department of Urban \& Environmental Policy, Tufts University, Medford, Massachusetts 02155 , USA. 